\title{
Experimental assessment of the formation of professional competencies of students who are future managers in higher educational institutions
}

\author{
M.V. Neparko ${ }^{1 *}$ \\ ${ }^{1}$ Kaluga State University named after K.E. Tsiolkovsky, Kaluga, Russia
}

\begin{abstract}
The author considers modern pedagogical technologies, which are reflected in the article. A special place is occupied by the experimental part-testing, which was attended by 60 students of $2-5$ courses of the university. The study showed that university students are characterized by insufficient knowledge of the language, culture, historical past, traditions and customs of their own and other peoples, as well as insufficient tolerance and goodwill, manifested in feelings, assessments and behavior towards representatives of other nationalities. On the basis of a scientific and analytical study of the formation of intercultural competencies among students of higher educational institutions, it became possible to draw an exhaustive conclusion about the need to introduce a course of lectures in the variable part of the curriculum, which includes a discipline of choice in the amount of $1 / 3$ at the level of higher education "master". Such lectures will allow you to delve deeper into the issues of intercultural and interethnic communication, the development of speech communication, which is due to the needs of professional practice.
\end{abstract}

\section{Problem statement}

Russia's entry into the Bologna Process has defined a fundamentally new approach to the paradigm of Russian education. In the scientific works of Russian and foreign scientists, various approaches to modeling professional intercultural competencies are considered. These approaches are formed in the process of cross-cultural interaction and doing business in another culture. Cross-cultural competence in business terms is sometimes referred to as global or transnational competence. Today, advanced technologies have enabled many cultures to integrate different intellectual capabilities. Therefore, it is extremely important that each manager has an optimal set of qualities for successful professional activity, which would determine his cross-cultural competence. The value of cross-cultural competence skills is becoming increasingly important for many international companies and is an important condition for survival in the global economy.

\footnotetext{
*Corresponding author: prof-ped.gpa@mail.ru
} 
In this regard, an integral part of the development of the disciplines of the humanities cycle of the higher school of the cycle should be the process of forming the professional intercultural competence of students, future managers.

Currently, higher education institutions face an important task - to develop and implement a course of lectures that, taking into account the socio-economic conditions in society, will help managers in the future to professionally solve intellectual, creative, managerial and production tasks. The quality of this training course should begin with the formation of the person's personality, the development of his spiritual and creative abilities, realized in his professional activity. Hence, the role of education is clear, designed to ensure the formation of such a person who is able to make qualitative changes in the field of their activities.

The study of a number of studies on the formation of professional competence in managers allows us to conclude that the main pedagogical goal of the formation of competence in managers and the criterion for determining the level of its formation is to teach managers a foreign language, the development of scientific and technological progress and the direction of economic development of the state.

Thus, there is a need to find new approaches at all levels of training of future managers and as a factor in improving the quality of their training, taking into account cross-cultural ties in the context of international academic and economic mobility.

Thus, the current conditions of our life impose fundamentally new requirements for business education from the point of view of intercultural communication. Training should be inductive, not prescriptive, i.e. it should start with a needs analysis, not with a predefined curriculum.

\subsection{The objective of the work}

To study the theoretical, methodological and practical approaches of domestic and foreign scientists, teachers of higher educational institutions to assess the formation of competencies in students of higher educational institutions, which can complement the pedagogical base. The theoretical basis of the research is the works of such domestic and foreign authors as M. Bennet [1], H.D. Brown [2], M. Bayram [3], S. Brian [4], L. Chen [5], D. Deardorff [6], A.E. Fantini [7], J.R. Gullahorn, J.E. Gullahorn [8], H. Hamilton, B.J. Richardson, B. Shuford [9], D. Hymes [10], M. Hammer [11], and others. The work of these researchers in the fields of pedagogy, sociology, social psychology and philosophy formed the basis of this study and became an important stage in the process of understanding the above problems. They made it possible to supplement the theoretical basis of the study with the necessary theoretical and practical data, theses and conceptual defining elements that allow us to actualize the need to solve the described problem and come to a pedagogical consensus.

\section{Materials and results of the study}

This study is aimed at studying the current situation of knowledge of cross-cultural competencies in management students and finding out how cross-cultural relations are accompanied by cross-cultural awareness, cross-cultural skills and cross-cultural knowledge. It is assumed that the test will reveal the level of knowledge of cross-cultural competencies of students-future managers. To implement the most effective conceptual research, we defined a range of tasks, which included:

1) Using a set of methods: included observation of students in the classroom, testing, analysis of the results of the formation of cross-cultural competence of students-future 
managers, obtained by testing.

2) Identify the cross-cultural skills and cross-cultural competencies that are most formed in students-future managers.

3) Determine the stages of the process of assessing the formation of students ' competencies [1].

4) What are the possible causes of the results?

Doctor of Pedagogical Sciences A.V. Khutorskoy offers the following definition of competence: a set of interrelated personality qualities (knowledge, skills, skills, methods of activity), set in relation to a certain range of subjects and processes, and necessary for highquality productive activity in relation to them.

The experimental work involved students of the 2nd and 5th year of the full-time department in the specialty "Customs" and teachers of the department "Customs" of the Kaluga State University named after K.E. Tsiolkovsky. The study presents a quantitative assessment of the indicators of the level of effectiveness of the formation of intercultural competence, determined by means of coefficients based on the methods of mathematical statistics. This category of managers is most in demand today in international business, as it is associated with the creation of foreign production facilities in Russia and the movement of goods to the foreign market.

The experimental work was carried out in two stages. The first stage is associated with the determination of the level of formation of cross - cultural competencies among 2ndyear management students at the initial stage of training. The second stage is associated with the determination of the level of formation of cross - cultural competencies among the 5th-year management students who are completing their training. 60 students took part in each experimental group.

During the experiment, a test consisting of 15 questions was developed (Table 1). The test was developed taking into account four aspects: cross-cultural awareness, cross-cultural attitudes, cross-cultural skills and cross-cultural knowledge, which help to explore the competence of people's cross-cultural communication. The questionnaires are mostly conducted during the break, and about a third of the questionnaires are from high school students in their dorm. 60 students from each group took part in the testing [12].

Table 1. Test results of 2nd and 5th year students of Kaluga State University named after K.E. Tsiolkovsky.

\begin{tabular}{|c|c|c|c|c|c|}
\hline & \multirow[t]{2}{*}{ Name of the competence Input diagnostics } & \multicolumn{2}{|c|}{$\begin{array}{c}\text { Frontier } \\
\text { diagnostics } \\
\text { 2nd year } \\
\text { students }\end{array}$} & \multicolumn{2}{|c|}{$\begin{array}{c}\text { Frontier } \\
\text { diagnostics } \\
\text { 5nd year } \\
\text { students }\end{array}$} \\
\hline & & Yes & No & Yes & No \\
\hline 1. & $\begin{array}{l}\text { Are you familiar with the concept of "cross-cultural } \\
\text { competence"? }\end{array}$ & 52 & 8 & 58 & 2 \\
\hline 2. & $\begin{array}{l}\text { Do you think that cross-cultural competencies are } \\
\text { important to you? }\end{array}$ & 47 & 13 & 56 & 4 \\
\hline 3. & $\begin{array}{l}\text { Do you think that the knowledge you receive in an } \\
\text { educational institution about cross-cultural competencies is } \\
\text { sufficient? }\end{array}$ & 29 & 31 & 36 & 24 \\
\hline 4. & $\begin{array}{l}\text { How do you assess your level of cross-cultural } \\
\text { competence? (high - "yes", low - "no") }\end{array}$ & 44 & 16 & 27 & 33 \\
\hline 5. & $\begin{array}{l}\text { Would you like to improve your level of intercultural } \\
\text { competence? }\end{array}$ & 36 & 24 & 55 & 5 \\
\hline 6. & $\begin{array}{l}\text { Do you consider ignorance or insufficient knowledge of a } \\
\text { foreign language to be a barrier to improving cross-cultural } \\
\text { competencies? }\end{array}$ & 53 & 7 & 45 & 15 \\
\hline 7. & Do you consider ignorance of the culture of foreign & 56 & 4 & 51 & 9 \\
\hline
\end{tabular}




\begin{tabular}{|c|c|c|c|c|c|}
\hline & $\begin{array}{l}\text { countries to be a barrier to improving cross-cultural } \\
\text { competencies? }\end{array}$ & & & & \\
\hline 8. & $\begin{array}{l}\text { Do you consider the lack of opportunities to communicate } \\
\text { with speakers of another culture to be a barrier to } \\
\text { improving cross - cultural competencies? }\end{array}$ & 53 & 7 & 48 & 12 \\
\hline 9. & Do you think that national identity separates people? & 40 & 20 & 22 & 38 \\
\hline 10. & $\begin{array}{l}\text { Do you think that a modern manager needs to possess } \\
\text { cross-cultural competencies? }\end{array}$ & 59 & 1 & 54 & 6 \\
\hline 11. & $\begin{array}{l}\text { How do you think cross-cultural competencies affect the } \\
\text { professional activity of a modern manager in an } \\
\text { international environment? }\end{array}$ & 59 & 1 & 53 & 3 \\
\hline 12. & $\begin{array}{l}\text { Do you think that cross-cultural competencies make it } \\
\text { difficult to adapt to new working conditions? }\end{array}$ & 38 & 22 & 22 & 38 \\
\hline 13. & $\begin{array}{l}\text { Are you ready to cooperate with representatives of any } \\
\text { nation, despite national differences? }\end{array}$ & 26 & 34 & 24 & 36 \\
\hline 14. & $\begin{array}{l}\text { Do you consider it necessary to introduce the discipline } \\
\text { "Cross-cultural competencies" into the educational process }\end{array}$ & 55 & 5 & 54 & 6 \\
\hline 15. & $\begin{array}{l}\text { Are the development of cross-cultural competencies a } \\
\text { motivation for the professional growth of a manager? }\end{array}$ & 51 & 9 & 47 & 13 \\
\hline
\end{tabular}

The analysis of the obtained data showed that the majority of the surveyed students are familiar with the concept of "intercultural competence" (students of the 2nd year-87\%, students of the 5th year-97.7), believe that:

- cross-cultural competencies are important for students (2nd year students-78\%, 5th year students-93.3\%);

- cross-cultural competencies influence the professional activity of a modern manager in an international environment ( 2 nd year students-99\%, 5th year students-88.3\%);

- the knowledge that is received in an educational institution about cross-cultural competencies is not enough (students of the 2 nd year - 48.5, students of the 5 th year- $60 \%$ );

- it is necessary to introduce the discipline "Cross-cultural competencies" into the educational process ( 2 nd year students- $91.7 \%$, 5th year students-90\%);

- осво the development of cross-cultural competencies is the motivation for the professional growth of the manager ( 2 nd year students- $85 \%$ th year students $-78.3 \%$ ).

The level of respondents about the need to introduce the discipline "Cross-cultural competencies" into the educational process showed a high level $(91.7 \%)$, which is explained by the desire of students-future managers to be competent in different cultures, to be able to navigate and evaluate situations, to take into account the norms and values of different cultures, to maintain relationships with people, to have emotional support, orientation to the approval of society, which is confirmed by the test results. The focus on the development of cross-cultural competencies for the professional growth of the manager was shown by $85.0 \%$ of the respondents, which indicates their interest in solving professional tasks, the desire to perform well, and focus on achieving the results of professional activity [12].

The analysis of the obtained data showed that the surveyed students of the 2 nd and 5 th courses have almost the same survey result. During the 2 nd, 3rd, 4th, and 5 th years of study, students did not acquire the necessary knowledge, skills, and skills in the field of cross-cultural competencies (Figure 1). A number of contradictions may explain this fact:

- the increased need for pedagogical theory and practice to reveal the regularities of the process of forming intercultural competencies in the future manager and the insufficient development of the pedagogical theory of intercultural competencies in the context of the globalization of the developing society; 
- the presence of criteria for assessing the knowledge, skills and competencies of future managers and the lack of diagnostic tools to determine the level of formation of cross-cultural competencies of future managers in the practice of training and the theory of pedagogy and the lack of scientific developments in the field of cross-cultural competencies and their implementation in the educational process. In a specific aspect, the research problems consist in the following contradictions: between the desire of students to gain knowledge in the field of intercultural competencies and the lack of an attitude to the professional activity of a cultural scientist, as well as their own uncertainty.

The results suggested that students are motivated to acquire special knowledge and develop the skills and abilities necessary to perform professional activities. Thus, we were convinced of the need to introduce a course of lectures in the variable part of the curriculum, which includes an elective discipline in the amount of $1 / 3$ at the level of higher education "master". Such lectures will allow you to delve deeper into the issues of intercultural and interethnic communication, the development of speech communication, which is due to the needs of professional practice. The course of lectures will expand the scope of professional knowledge related to the manifestation of cross-cultural competencies in the process of teaching a foreign language, causing interest in professional activities and the need for transformation of educational and professional activities [13].

Further, in the course of the ascertaining experiment, the indicators of the cognitive component of intercultural competence were evaluated. The results of the assessments revealed a low level of formation of indicators of the cognitive component of intercultural competence among students-future managers. Students have a lack of awareness of special knowledge that reveals the specifics of cross-cultural competencies in the professional activity of a manager. Students find it difficult to define the term "cross-cultural competence", which is confirmed by the conducted testing of students who find it difficult to define the concept of "cross-cultural competence" (from 4 to 13.3\%).

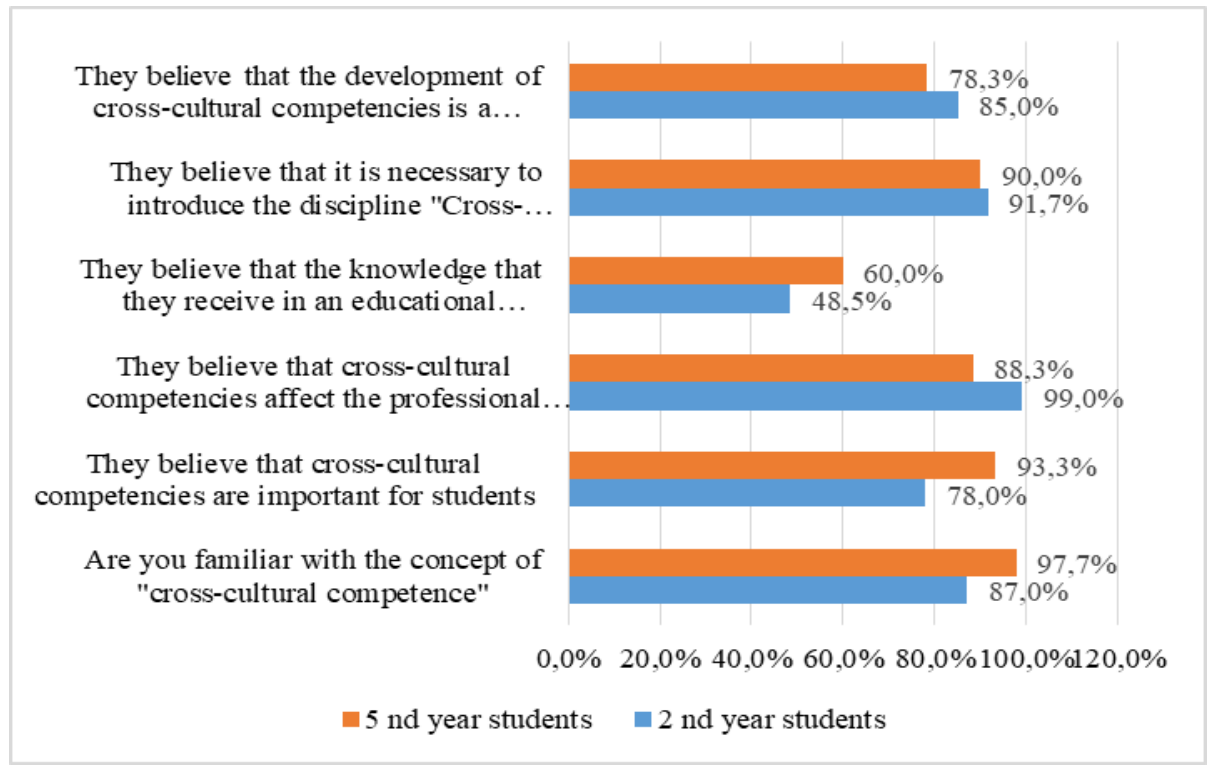

Fig. 1.Test results of 2nd and 5th year students of Kaluga State University named after K.E. Tsiolkovsky. 
A comparison of assessments of the indicators of the activity component of intercultural competence showed a low level of their formation, which is explained by the lack of experience in intercultural interaction. The lowest result was obtained in the indicator "Are you ready to cooperate with representatives of any nation, despite national differences" $(43.3 \%$ and $40.0 \%)$, which indicates that students-future managers have no experience of professional behavior in the context of intercultural interaction [12].

The formative experiment was aimed at developing and testing a system for the formation of cross-cultural competencies in students-future managers, its purpose was to include students in the process of cultural, communicative, contextual, personality-oriented and personal-activity approaches using active forms and methods of teaching cross-cultural competencies in the process of professional training in higher education [14]. It was necessary for the experiment to design and introduce new content into the general system of professional training methods for tracking the results of experimental work; to introduce into the learning process the formation of value-motivational, cognitive, activity and reflexive components of intercultural competence. The hypothesis of the formative experiment was based on the assumption that active methods affect the formation of the intercultural competence of students-future managers, which leads to positive changes in the assessments of the indicators of value-motivational, cognitive, activity and reflexive components of the intercultural competence of students-future managers.

A comparative analysis of the results of the ascertaining and formative experiments showed that the level of formation of the intercultural competence of students-future managers in comparison with the ascertaining experiment tends to increase. At the same time, students expressed their wishes to participate in trainings on the formation of intercultural competence in the next year $(40 \%)$, as well as to increase the number of practical classes in the discipline "Intercultural Competence" (37\%). As a result, studentsfuture managers among the motives of satisfaction with the results of the formation of cross-cultural competence called the desire to achieve the results of professional activity (47\%), increasing opportunities for self-realization in professional activities $(35 \%)$, expanding the range of professional skills and increasing the level of self-esteem (42\%). A comparative analysis of the results of the ascertaining and formative experiments revealed a positive dynamics of the indicators of the value-motivational component of intercultural competence.

In the course of the forming experiment, based on the comparison of its results with the materials of the ascertaining experiment, the dominant indicators in each component were determined. The dominant indicator in the value-motivational component according to the results of the ascertaining experiment is the indicator "the need for the development and transfer of social experience", and according to the results of the formative experiment "the need to achieve results in performing the functions of professional activity", which indicates their interest in solving professional tasks, the desire to perform the work as best as possible, focus on achieving the results of professional activity, the shift in students ' motivation to professional values, which is achieved by reading texts in the specialty within the context approach [5]. The cognitive component of intercultural competence in the course of the ascertaining experiment was dominated by the indicator "knowledge of cultural values transmitted in the process of transmitting social experience", according to the results of the formative component - the indicator "knowledge of the functions performed by cultural specialists", which indicates the assimilation of the content of the professional activities of managers and a full understanding of the specifics of their future professional activities, since the content of training in intercultural competencies included thematic sections that reveal the specifics of the professional activities of managers. The dominant indicator of the activity component according to the materials of the ascertaining experiment is the indicator "the ability to apply the rules of etiquette in the situation of 
intercultural interaction", according to the materials of the forming experiment-the indicator "the ability to build utterances as units of speech in the process of translating social experience", which confirms the communicative-oriented nature of teaching intercultural competencies and is due to the use of active methods in these classes, imitating the real professional activities of managers. In the reflexive component of the intercultural competence of students-future managers, the dominant indicator according to the results of the ascertaining experiment was the indicator "the ability to analyze the behavior of partners and their own in the situation of intercultural interaction", according to the results of the formative experiment - the indicator "the ability to analyze, evaluate and selfevaluate the results of professional activity in the course of intercultural interaction", which allows us to conclude that the role of reflection in the performance of professional activities increases, the ability to analyze the professional situation and find the right solution is formed, which was facilitated by role-playing and business games and discussion after games of various professional situations in foreign language classes [6].

\section{Conclusions}

The results of the study show that the topic of cross-cultural competencies remains relevant for further research. Investigation options suggest a variety of combinations, opportunities for future research, since most people meeting with speakers of another culture can find themselves in one or more models that go through different stages of the development of cross-cultural competencies. This means that the evolution of cross-cultural communication is limitless and at each stage it is possible to achieve a certain level of cross-cultural sensitivity, maturity, adaptation and acculturation, different from the current one. Currently, cross-cultural competencies can be considered as the ability to form a cultural identity, which implies knowledge of the language, values, norms, and standards of behavior of another communicative community. With this approach, the assimilation of the maximum amount of information and adequate knowledge of a different culture becomes the main goal of the communication process [5].

To develop cross-cultural competence and the ability to communicate with representatives of different cultures, professional training of managers is necessary, which will contribute to the development of international activities in general and modern business in particular.

This requires modern pedagogical technologies that will provide an opportunity to teach university students cross-cultural competencies, different cultures, traditions and customs of their own and other peoples, as well as lack of tolerance and goodwill, manifested in feelings, assessments and behavior towards representatives of other nationalities. On the basis of a scientific and analytical study of the formation of intercultural competencies among students of higher educational institutions, it became possible to draw an exhaustive conclusion about the need to introduce a course of lectures in the variable part of the curriculum, which includes a discipline of choice in the amount of $1 / 3$ at the level of higher education "master". Such lectures will allow you to delve deeper into the issues of intercultural and interethnic communication, the development of speech communication, which is due to the needs of professional practice.

\section{References}

1. M.J. Bennett, Basic concepts of intercultural communication, 272 (Yarmouth, ME: Intercultural Press, 1998) 
2. H.D. Brown, Principles of language learning and teaching, 285 (Englewood Cliffs, NJ: Prentice-Hall, 1987)

3. M. Bayram, Teaching and Assessing Intercultural Communicative Competence, 124 (Multilingual Matters, 1997)

4. S. Brian, A Model of Intercultural Communication Competence, International Journal of Intercultural Relations, 10, 380-392 (2000)

5. L. Chen, and Z. Wang, A Study on the Status Quo of Chinese College Students' Intercultural Communication Competence, Chinese Studies, 7, 164-173 (2018)

6. D.K. Deardorff, Identification and assessment of intercultural competence as astudent outcome of internationalization, Journal of Studies in Intercultural Education, 10, 241266 (2006)

7. A.E. Fantini, Language, culture, and world view: Exploring the nexus, International Journal of Intercultural Relations, 19, 143-153 (1995)

8. J.R. Gullahorn, J.E. Gullahorn, An extension of the U-curve hypothesis, Journal of Social Issues, 3, 33-47 (1962)

9. H. Hamilton, B.J. Richardson, B. Shuford, Promoting multicultural education: A holistic approach, College Student Affairs Journal, 18, 5-17 (1998)

10. D. Hymes, About communicative competence, Philadelphia: University of Pennsylvania Press, 22, 23-24 (1971)

11. M.R. Hammer, Behavioral dimensions of intercultural effectiveness: A replication and extension, International Journal of Intercultural Relations, 11, 65-88 (1987)

12. M.V. Neparko, Modern methods of development of intercultural competencies through education, International Journal of Humanities and Natural Sciences, 1 (51), $141(2021)$

13. M.J. Bennett, A developmental approach to training for intercultural sensitivity, International Journal of Intercultural Relations, 10, 179-196 (1986)

14. K. Jebahi, A Perspective-Based Reading of Culture in English Language Teaching: From the Conventional Perspective to the Intercultural Language Teaching Perspective, Open Journal of Modern Linguistics, 3, 216-222 (2013) 